\title{
Clostridium Difficile Infection: The Scope of the Problem
}

\author{
Erik Dubberke, MD, MSPH${ }^{\star}$
}

Division of Infectious Disease, Washington University School of Medicine, St Louis, Missouri.

Clostridium difficile infection (CDI) is increasingly common, and it is associated with significant morbidity, mortality, and cost burden for patients and the healthcare system. The severity and rates of recurrent CDI and associated mortality are also increasing. This article is an overview of the changes in CDI epidemiology that have occurred since the turn of the century and the current scope of the problem. The 3 articles that follow in this supplement address the diagnosis and treatment of initial and recurrent CDI, and current practice guidelines for the prevention and control of $\mathrm{CDI}$ in the hospital setting. Journal of Hospital Medicine 2012;7:S1-S4. (C 2012 Society of Hospital Medicine
Clostridium difficile is a gram-positive, spore-forming, toxin-producing, anaerobic bacillus that was established as the causative pathogen of most cases of antibiotic-associated colitis in $1978 .^{1,2}$ The spectrum of possible clinical presentations of $C$. difficile range from asymptomatic colonization, uncomplicated diarrhea, severe pseudomembranous colitis, paralytic ileus, to sepsis and death, with a mortality rate upwards of $80 \%$ in fulminant cases requiring colectomy. ${ }^{3}$

Vegetative C. difficile cells die rapidly on dry surfaces, but they have been found to remain viable for up to 6 hours on moist surfaces in room air. ${ }^{4}$ Spores shed from the gastrointestinal (GI) tract, however, are highly resistant to common hospital disinfectants, and can survive in the environment for many months. ${ }^{2} \mathrm{C}$. difficile spores are primarily transmitted from patient to patient on the hands or equipment of healthcare workers. ${ }^{2}$ Once spores are ingested and reach the GI tract, they germinate in the vegetative form. ${ }^{2,5}$ In the GI tract, C. difficile causes disease by the production of toxins, primarily toxins $\mathrm{A}$ and $\mathrm{B}$, both of which cause severe inflammation. ${ }^{5}$ Toxin $\mathrm{A}$ attracts neutrophils and monocytes, and toxin B breaks down colonic epithelial cells. ${ }^{5}$ Both of these mechanisms lead to colitis, formation of pseudomembranes, and watery diarrhea. ${ }^{5}$

After alteration of the healthy colonic bacterial flora, the immune response to $C$. difficile toxins appears to play a major role in determining host susceptibility to C. difficile infection (CDI). ${ }^{5,6}$ Those with antitoxin immunity are more likely to become symptomless carriers than patients without preexisting immunity. ${ }^{3}$ More

*Address for correspondence and reprint requests: Erik Dubberke, MD, MSPH, Assistant Professor of Medicine, Division of Infectious Disease, Washington University School of Medicine, 660 S Euclid Ave, Box 8051, St Louis, MO 63110; Telephone: 314-454-8293; E-mail: edubberk@DOM.wustl.edu

Additional Supporting Information may be found in the online version of this article.

Received: April 16, 2011; Revised: December 14, 2011; Accepted: January 1, 2012

2012 Society of Hospital Medicine DOI 10.1002/jhm.1916

Published online in Wiley Online Library (Wileyonlinelibrary.com). than $60 \%$ of healthy adults have protective immunity against a primary CDI, demonstrated by detectable serum IgG and IgA to both toxins $\mathrm{A}$ and $\mathrm{B}$, as a consequence of childhood immunity or frequent exposure to C. difficile in the environment. ${ }^{3}$ After a primary episode of CDI, many patients acquire protective immunity against $C$. difficile toxins, seen as significantly higher serum concentrations of IgM against C. difficile toxin by the third day from onset of diarrhea, and significantly higher serum concentrations of IgG against toxin $\mathrm{A}$ by the 12 th day. $^{7}$ Patients who experience recurrent CDI lack development of this protective immunity to C. difficile. ${ }^{6,7}$

\section{INCIDENCE IS ON THE RISE}

During the past decade, rates of CDI have increased steadily to levels not previously seen. A report published by the Agency of Healthcare Research and Quality demonstrated that the number of CDI diagnoses on hospital discharge more than doubled in the United States from 139,000 to 301,200 between 2000 and 2005 (Figure 1). ${ }^{8}$ Examination of a more recent Nationwide Inpatient Sample (NIS) indicates continuation of this trend, with nearly 350,000 CDI diagnoses recorded upon discharge from acute care hospitals in 2008. ${ }^{9}$ Of note, in 2006 the state of Ohio mandated CDI reporting from both hospitals and nursing homes. It was estimated there were more than 18,000 cases of CDI during this year, of which more than $60 \%$ were diagnosed in nursing homes. ${ }^{10}$ Based on the 2008 NIS data and the data from Ohio, it is conceivable there were as many as 1 million cases of CDI in the US in 2008.

This increased incidence of CDI contrasts with several other healthcare-associated infections, which have declined in incidence over the last decade ${ }^{11-13}$ C. difficile is the most common causative agent of healthcare-associated infections in some areas. A cohort study of common infections among inpatients at 30 community hospitals in the Duke Infection Control Outreach Network conducted between January 1, 2008 and June 30, 2009 found the incidence of CDI cases was 0.26 cases per 1000 patient-days, which was higher than the incidence of 


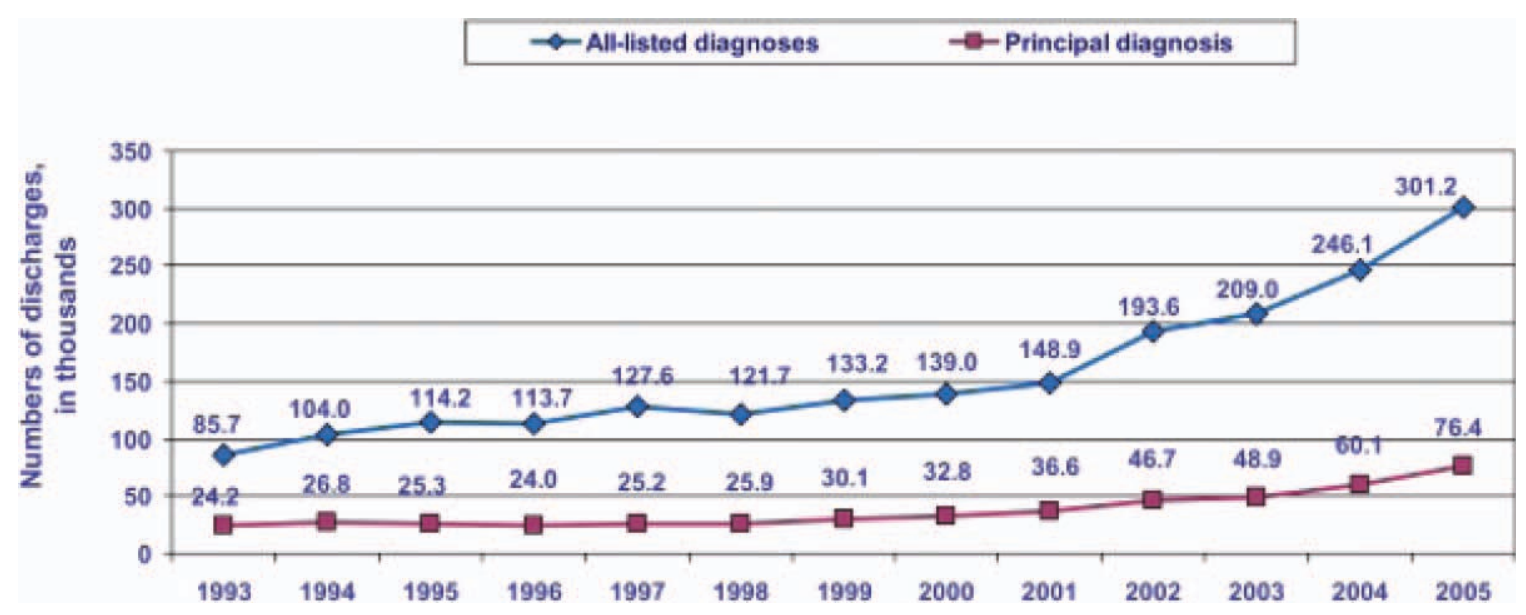

FIG. 1. Trends in hospital stays associated with Clostridium difficile-associated disease, $1993-2005 .^{8}$

methicillin-resistant Staphylococcus aureus (MRSA) at 0.22 cases per 1000 patient-days. ${ }^{14}$ Another study utilizing the NIS data found that, while vancomycin-resistant enterococcus and pseudomonas infections remained stable, CDI increased in many areas of the country and was more common than MRSA in some areas. ${ }^{15}$

\section{HYPERVIRULENT STRAIN OF C. DIFFICILE}

In the early 2000s, an epidemic and hypervirulent strain of C. difficile emerged in North America and Europe that altered the epidemiology of CDI. ${ }^{16}$ Due to multiple different methods for molecular typing of C. difficile, this strain has several names depending on the method of typing performed. The most common names for this strain are BI (REA typing), NAP1 (pulsed field gel electrophoresis), and 027 (PCR-ribotyping). This strain has become the predominant strain of $C$. difficile in some areas, accounting for more than $80 \%$ of CDI cases in some areas. ${ }^{3}$

The characteristics of this particular strain epidemic in North America typically include:

- A deletion in the $t c d$ gene that downregulates toxin production, which renders the gene nonfunctional in the epidemic strain. Some in vitro data have demonstrated that this epidemic strain produces 16-fold higher concentrations of toxin A and 23-fold higher concentrations of toxin B than nonepidemic strains of C. difficile. ${ }^{17}$

- Production of a third toxin, called binary toxin CDT. The role of this toxin in the pathogenesis of CDI is not clear, but the presence of this toxin has been associated with more severe CDI-related diarrhea. ${ }^{2,16}$

- High-level resistance to fluoroquinolones, including moxifloxacin and gatifloxacin., ${ }^{5,16}$ It has been theorized that increasing use of fluoroquinolones during the past decade may have provided a selective advantage for the BI/NAP1/027 strain to predominate. ${ }^{2}$

- Production of more spores than other strains of $C$. difficile. ${ }^{17,18}$ This may increase its ability to contaminate the environment and be transmitted in a healthcare facility.

\section{SEVERITY IS INCREASING}

Paralleling the increased prevalence of CDI, C. difficile infections are generally becoming more severe. In Sherbrooke, Quebec, Canada, which experienced a dramatic outbreak of CDI associated with increased CDI severity, the cumulative 1-year attributable mortality was nearly $37 \%$ (60 of 161 CDI cases) in a hospital case review of nonsurgical admissions between January 2003 and June 2004. ${ }^{19}$ In St Louis, Missouri in 2003 , a $5.7 \% 180$-day mortality rate was reported in an endemic setting. ${ }^{20}$ Among the $24 \%$ of patients readmitted within 180 days of discharge (4207 of $17,492)$ in this retrospective case review, patients with CDI were more than twice as likely as non-CDI patients to be readmitted to the hospital $(52 \%$ vs $23 \%, \mathrm{~N}=4207) .{ }^{20}$ Furthermore, patients with CDI were significantly more likely to require discharge to a long-term care facility $(32 \%)$ than non-CDI controls $(23 \%){ }^{19}$

Based on NIS data for CDI-related hospitalizations between 2000 and 2005, the crude, age-adjusted casefatality rate rose from $1.2 \%$ in 2000 to $2.2 \%$ in 2004. ${ }^{21}$ This increase was mirrored by a doubling of CDI cases admitted for hospitalization during the same 6-year period. ${ }^{21}$ According to the investigators, these findings indirectly confirm that the doubling in CDI deaths is attributable to an increase in C. difficile virulence. $^{21}$ A 6-month prospective surveillance of CDI patient outcomes in 29 Canadian hospitals was conducted by the Canadian Nosocomial Infection Surveillance Program (CNISP) beginning in November $2004 .^{22}$ At 30 days after onset of CDI, the percentage of deaths directly or indirectly attributable to CDI was $5.7 \%$, which represented an almost 4-fold increase over CDI-attributable deaths recorded in the 1997 CNISP survey. ${ }^{22}$ Overall 30-day mortality was retrospectively analyzed among patients with CDI in a St Louis, Missouri 1200-bed teaching hospital intensive care unit (ICU) over a 2-year period (2004- 
TABLE 1. Economic Burden of CDI

\begin{tabular}{|c|c|c|c|c|}
\hline Study & Patient Population & $\begin{array}{l}\text { Estimated Attributable } \\
\text { Cost per Episode* }\end{array}$ & Increase in LOS, days ${ }^{\dagger}$ & $\begin{array}{c}\text { Estimated Annual } \\
\text { Attributable Cost, US }\end{array}$ \\
\hline Kyne et al ${ }^{40}$ & Two medical wards $\$(n=40)$ & $\$ 3669$ & 3.6 & \$1.1 billion \\
\hline Dubberke et al $\left.\right|^{39}$ & Nonsurgical patients" $(n=439)$ & $\$ 2454-\$ 3240^{\mathbb{I}}$ & 3.0 & \$897 million-\$1.3 billion ${ }^{\#}$ \\
\hline O'Brien et al ${ }^{41}$ & Massachusetts discharge database $(n=3692)^{\star *}$ & $\begin{array}{l}\text { Primary diagnosis: } \$ 10,212 ; \\
\quad \text { secondary diagnosis: } \$ 13,675^{\dagger \dagger}\end{array}$ & $\begin{array}{l}\text { Primary diagnosis: 6.4; } \\
\text { secondary diagnosis: } 2.9\end{array}$ & $\$ 3.2$ billion \\
\hline
\end{tabular}

Abbreviations: CDI, Clostridium difficile infection; LOS, length of stay.

*Adjusted, estimated cost for inpatient course of therapy attributable to $C$. difficile, per event.

${ }^{\dagger}$ Adjusted, estimated, median length of hospital stay for therapy complicated by C. difficile, per event.

Estimated overall annual cost of management of inpatient CDI in the United States.

Cohort of patients with CDI within group of patients consecutively admitted to 1 of 2 medical wards with infections that required treatment with antibiotics from January 5, 1998 through May 22, 1998 ( $N=264$ ).

"Cohort of patients with CDI within group of patients consecutively admitted to a 1250-bed tertiary care hospital from January 1, 2003 through December 31, 2003 ( $N=24,691$ ).

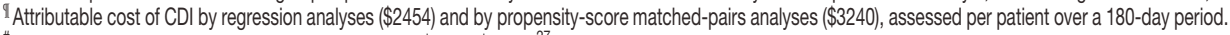

\# Based on 180-day cost of inpatient CDI in this study $(\$ 5042-\$ 7179),{ }^{27}$ times 178,000 discharges from short-stay hospitals in the United States for C. difficile-associated diarrhea cases in $2003{ }^{41}$

${ }^{*}$ All hospital discharges in Massachusetts in 2000 ( $\left.N=450,000\right)$.

${ }^{t \dagger}$ Patients admitted from the community or a subacute care facility primarily for $\mathrm{C}$. difficile-associated diarrhea were defined as a primary diagnosis case. A secondary diagnosis was defined as a $\mathrm{C}$. difficile-associated diarrhea stay during which C. difficile-associated diarrhea was a secondary diagnosis where the principal diagnosis did not appear to be directly related to C. difficile-associated diarrhea.

2005). ${ }^{23}$ The 30-day crude mortality among 278 patients admitted to the ICU with CDI was $37 \%$ ( $\mathrm{n}=$ 102), and mortality directly attributable to CDI in these critically ill patients was $6 \% .^{23}$ The number of deaths in the United States due to CDI increased sharply from 793 patients in 1999 to 6225 patients in $2006 .^{24}$ In 2006, it ranked among the top 20 causes of death for those aged 65 years and older. ${ }^{24}$

\section{INCREASE IN TREATMENT FAILURES}

In addition to being more severe, there have been several reports of increases in CDI treatment failures and/ or increases in recurrent CDI. ${ }^{6}$ Recent studies indicate there may be more metronidazole treatment failures regardless of whether the infecting strain is the BI/ NAP1/027 strain, despite a lack of laboratory evidence indicating resistance to metronidazole. ${ }^{25-29}$ Regardless of the initial therapy chosen, patients must be carefully monitored to ensure they are responding appropriately to treatment and their condition is not deteriorating. ${ }^{29}$ Some of the original trials of CDI treatments found relapse rates as low as $5 \%$ to $15 \% .{ }^{30}$ More recent data indicate relapse occurs after $\sim 30 \%$ of initial CDI episodes, and as frequent as $65 \%$ if the patient has had multiple prior CDI episodes. $3,6,31$

\section{COMMUNITY-ASSOCIATED CDI}

The epidemiology of community-associated CDI may also be changing. Virulent strains, which cause more severe disease in high-risk patients, may also cause more frequent, severe disease in populations previously thought to be at low risk. Some studies have found an increase in community-associated CDI in otherwise healthy individuals with little or no exposure to a healthcare facility. Although antimicrobial exposure remains the most important risk factor for community-associated CDI, antimicrobial exposure is less common in community-associated CDI than healthcare-associated CDI. ${ }^{32-35}$

In a Canadian study, the rate of diagnosed community-acquired CDI cases was stable at about 22 cases per 100,000 patient-years per calendar year between
1998 and 2002, but rose steadily for the next 2 years to 53 cases per 100,000 patient-years in $2004 .{ }^{33}$ Similar results were seen in the United Kingdom, with an exponential increase from fewer than 1 case per 100,000 person-years in 1994 to 22 cases per 100,000 person-years in $2004 .^{32}$ There are currently no comprehensive longitudinal studies in the United States investigating the incidence of purely communityacquired CDI where a patient had no prior hospital exposure. However, regional surveys have reported an incidence of community-acquired CDI of 12 cases per 100,000 person-years during 1992 to $1994,{ }^{36} 7.6$ cases per 100,000 person-years in $2005,{ }^{37}$ and 6.9 cases per 100,000 person-years in $2006 .{ }^{34,37}$

One patient population generally thought to be at low risk for CDI that may be at increased risk for severe CDI is pregnant women. In one study 419 infectious disease consultants who responded to a survey conducted by the Emerging Infections Network had seen or were aware of 55 cases of CDI in peripartum women. ${ }^{38}$ There were 21 cases with complications, including 10 relapses and 5 cases of toxic megacolon. ${ }^{38}$ In a prior report of severe CDI among 10 peripartum women, 3 women died and 3 infants ( 2 were twins) were stillborn. ${ }^{38}$ This data emphasizes why clinicians must have a high index of suspicion for CDI, and should be aware of the potential for severe outcomes, even in patients traditionally considered to be at low risk. ${ }^{38}$

\section{ECONOMIC IMPACT OF CDI}

The economic burden of CDI in the United States is staggering, with estimates ranging from $\$ 1.1$ to $\$ 3.2$ billion annually (Table 1). ${ }^{39-41}$ These estimates are based on the cost of caring for patients with CDI in acute care facilities and are primarily driven by increased length of stay in the hospital due to CDI. These data also predate the emergence of the BI/ NAP1/027 strain. Therefore, the costs of CDI are likely higher than these estimates due to the increases in CDI severity seen since these studies were performed. It is important to note that these studies did not include patients diagnosed and treated in nursing 
homes or the community, nor the increase in costs due to discharge to a long-term care facility. ${ }^{39}$

\section{SUMMARY}

C. difficile infections are becoming more prevalent and more severe. The issue is sufficiently serious that healthcare-onset CDI has recently been called a "major public health threat." 42 For this reason, efforts to combat virulent C. difficile should include good antimicrobial stewardship, effective infection control, and control of environmental factors that promote transmission. ${ }^{35}$ Healthcare professionals who oversee the care of inpatients should act as catalysts for improvement by taking a leadership role in the multidisciplinary approach needed to reduce the morbidity, mortality, and cost burden for patients and the healthcare system.

Disclosure: Consultant: Merck \& Co, Optimer Pharmaceuticals, Pfizer, Steris Corporation; Speakers' Bureau: Cubist Pharmaceuticals, ScheringPlough; Grant/Research Support: Merck \& Co, Optimer Pharmaceuticals. The author received support for travel and an honorarium from Paradigm Medical Communications for time and expertise spent writing this article.

\section{References}

1. Bartlett JG. Narrative review: the new epidemic of Clostridium difficileassociated enteric disease. Ann Intern Med. 2006;145(10): 758-764.

2. Association for Professionals in Infection Control and Epidemiology, Inc (APIC). Guide to the elimination of Clostridium difficile in healthcare settings. Available at: http://www.apic.org/Content/NavigationMenu/PracticeGuidance/APICEliminationGuides/C.diff_Elimination guide_logo.pdf. 2008. Accessed October 8, 2011.

3. Norén T. Clostridium difficile and the disease it causes. Methods Mol Biol. 2010;646:9-35.

4. Jump RLP, Pultz MJ, Donskey CJ. Vegetative Clostridium difficile survives in room air on moist surfaces and in gastric contents with reduced acidity: a potential mechanism to explain the association between proton pump inhibitors and C. difficile-associated diarrhea?Antimicrob Agents Chemother. 2007;51(8): 2883-2887.

5. Sunenshine RH, McDonald LC. Clostridium difficile-associated disease: new challenges from an established pathogen. Cleve Clin J Med. 2006;73(2): 187-197.

6. Kelly CP. A 76-year-old man with recurrent Clostridium difficileassociated diarrhea: review of C difficile infection. JAMA. 2009; 301(9): 954-962.

7. Kyne L, Warny M, Qamar A, Kelly C. Association between antibody response to toxin $\mathrm{A}$ and protection against recurrent Clostridium difficile diarrhoea. Lancet. 2001;357(9251): 189-193.

8. Elixhauser A, Jhung M.Clostridium difficile-associated disease in US hospitals, 1993-2005. Healthcare Cost and Utilization Project. Statistical Brief \#50. April 2008. Available at: http://www.ncbi.nlm.nih. gov/books/NBK56038/pdf/sb50.pdf. Accessed December 12, 2011.

9. Agency of Healthcare Research and Quality. Healthcare Cost and Utilization Project Database. Available at: http://www.hcup-us.ahrq. gov/nisoverview.jsp. Accessed April 2011.

10. Campbell RJ, Giljahn L, Machesky K, et al. Clostridium difficile infection in Ohio hospitals and nursing homes during 2006. Infect Control Hosp Epidemiol. 2009;30(6): 526-533.

11. Burton DC, Edwards JR, Srinivasan A, et al. Trends in catheter-associated urinary tract infections in adult intensive care units-United States, 1990-2007. Infect Control Hosp Epidemiol. 2011;32(8): 748-756.

12. Burton DC, Edwards JR, Horan TC, et al. Methicillin-resistant Staphylococcus aureus central line-associated bloodstream infections in US intensive care units, 1997-2007. JAMA. 2009;301(7): 727-736.

13. Pronovost $\mathrm{P}$, Needham D, Berenholtz S, et al. An intervention to decrease catheter-related bloodstream infections in the ICU. N Engl J Med. 2006;355(26): 2725-2732.

14. Miller BA, Chen LF, Sexton DJ, Anderson DJ.The impact of hospitalonset healthcare facility associated (HO-HCFA) Clostridium difficile infection (CDI) in community hospitals: surpassing methicillin-resistant Staphylococcus aureus (MRSA) as the new superbug [abstract 386]. Presented at: The Fifth Decennial International Conference on Healthcare-Associated Infections (ICHAI). March 20, 2010; Atlanta, GA.

15. Zilberberg MD, Shorr AF, Kollef MH. Growth and geographic variation in hospitalizations with resistant infections, United States, 20002005. Emerg Infect Dis. 2008;14(11): 1756-1758.
16. McDonald LC, Killgore GE, Thompson A. An epidemic, toxin genevariant strain of Clostridium difficile. New Engl J Med. 2005; 353(23): 2433-2441.

17. Warny M, Pepin J, Fang A, et al. Toxin production by an emerging strain of Clostridium difficile associated with outbreaks of severe disease in North America and Europe. Lancet. 2005;366(9491): 1079-1084.

18. Åkerlund T, Persson I, Unemo M, et al. Increased sporulation rate of epidemic Clostridium difficile type 027/NAP1. J Clin Microbiol. 2008;46(4): 1530-1533.

19. Pépin J, Valiquette L, Cossette B. Mortality attributable to nosocomial Clostridium difficile- associated disease during an epidemic caused by a hypervirulent strain in Quebec. Can Med Assoc J. 2005; 173(9): 1037-1042.

20. Dubberke ER, Butler AM, Reske KA, et al. Attributable outcomes of endemic Clostridium difficile-associated disease in nonsurgical patients. Emerg Infect Dis. 2008;14:1031-1038.

21. Zilberberg MD, Shorr AF, Kollef MH. Increase in adult Clostridium difficile-related hospitalizations and case-fatality rate, United States, 2000-2005. Emerg Infect Dis. 2008;14(6): 929-931.

22. Gravel D, Miller M, Simor A, et al. Health care-associated Clostridium difficile infection in adults admitted to acute care hospitals in Canada: a Canadian Nosocomial Infection Surveillance Program study. Clin Infect Dis. 2009:48(5);568-576.

23. Kenneally C, Rosini JM, Skrupky LP, et al. Analysis of 30-day mortality for Clostridium difficile-associated disease in the ICU setting. Cheat. 2007;132(2): 418-424.

24. Heron M, Hoyert DL, Murphy SL, et al. Deaths: final data for 2006. Natl Vital Stat Rep. 2009;57(14): 1-134.

25. Fernandez A, Anand G, Friedenberg F. Factors associated with failure of metronidazole in Clostridium difficile-associated disease. I Clin Gastroenterol. 2004;38(5): 414-418.

26. Musher DM, Aslam S, Logan N, et al. Relatively poor outcome after treatment of Clostridium difficile colitis with metronidazole. Clin Infect Dis. 2005;40(11): 1586-1590.

27. Pépin J, Alary ME, Valiquette L, et al. Increasing risk of relapse after treatment of Clostridium difficile colitis in Quebec, Canada. Clin Infect Dis. 2005;40(11): 1591-1597.

28. Belmares J, Gerding DN, Parada JP, et al. Outcome of metronidazole therapy for Clostridium difficile disease and correlation with a scoring system. J Infect. 2007;55(6): 495-501.

29. Centers for Disease Control and Prevention. Information about the current strain of Clostridium difficile. Available at: http:// www.cdc.gov/HAI/organisms/cdiff/Cdiff-current-strain.html. Last updated: January 25, 2011. Accessed October 9, 2011.

30. Wenisch C, Parschalk B, Hasenhündl M, et al. Comparison of vancomycin, teicoplanin, metronidazole, and fusidic acid for the treatment of Clostridium difficile-associated diarrhea. Clin Infect Dis. 1996; 22(5): 813-818.

31. McFarland LV, Elmer GW, Surawicz CM. Breaking the cycle: treatment strategies for 163 cases of recurrent Clostridium difficile disease. Am J Gastroenterol. 2002;97(7): 1769-1775.

32. Dial S, Delaney JA, Barkun AN, Suissa S. Use of gastric acid-suppressive agents and the risk of community-acquired Clostridium difficileassociated disease. JAMA. 2005;294(23): 2989-2995.

33. Dial S, Kezouh A, Dascal A, Barkun A, Suissa S. Patterns of antibiotic use and risk of hospital admission because of Clostridium difficile infection. Can Med Assoc J. 2008;179(8): 767-772.

34. Centers for Disease Control and Prevention. Severe Clostridium difficile-associated disease in populations previously at low risk-four states, 2005. MMWR. 2005;54(47): 1201-1205.

35. Owens RC. Clostridium difficile-associated disease: an emerging threat to patient safety: insights from the Society of Infectious Diseases Pharmacists. Pharmacotherapy. 2006;26(3): 299-311.

36. Levy DG, Stergachis A, McFarland LV, et al. Antibiotics and Clostridium difficile in the ambulatory care setting. Clin Ther. 2000; 22(1): 91-102.

37. Centers for Disease Control and Prevention. Surveillance for communityassociated C. difficile -Connecticut, 2006. MMWR. 2008;57:340-343.

38. Rouphael NG, O'Donnell JA, Bhatnagar J, et al. Clostridium diffcile-associated diarrhea: an emerging threat to pregnant women. Am J Obstet Gynecol. 2008;198(6):635.e1-635.e6.

39. Dubberke ER, Reske KA, Olsen MA, et al. Short- and long-term attributable costs of Clostridium difficile-associated disease in nonsurgical inpatients. Clin Infect Dis. 2008;46(4): 497-504.

40. Kyne L, Hamel MB, Polavaram R, Kelly CP. Health care costs and mortality associated with nosocomial diarrhea due to Clostridium difficile. Clin Infect Dis. 2002;34(3): 346-353.

41. O'Brien JA, Lahue BJ, Caro JJ, Davidson DM. The emerging infectious challenge of Clostridium difficile-associated disease in Massachusetts hospitals: clinical and economic consequences. Infect Control Hosp Epidemiol. 2007;28(11): 1219-1227.

42. Chopra T, Marchaim D, Alangaden G, Kaye KS, Taylor T. National Clostridium difficile infection (CDI) related hospitalizations approaches MRSA related hospitalizations. The need for antibiotic stewardship program [poster 94]. Presented at: The SHEA 2011 Annual Scientific Meeting. April 2, 2011; Dallas, TX. 